\title{
STRESS AND EXERCISE AMONG THE JAPANESE ELDERLY
}

\author{
Neal Krause, ${ }^{1,2}$ Linda Goldenhar, ${ }^{2}$ Jersey Liang,,${ }^{1,2}$ Gina Jay ${ }^{2}$ and Daisaku Maeda ${ }^{3}$ \\ ${ }^{1}$ School of Public Health and ${ }^{2}$ Institute of Gerontology, University of Michigan, 1420 Washington \\ Heights, Ann Arbor, MI 48109-2029, U.S.A. and ${ }^{3}$ Japan School of Social Work and the Tokyo \\ Metropolitan Institute of Gerontology, 35-2 Sakae-Cho, Itabashi-Ku, Tokyo, 173 Japan
}

\begin{abstract}
This study seeks to replicate and extend research on the stress process by examining the relationships among stress, social support, physical exercise, and depressive symptoms with data provided by a recent nationwide survey of older adults in Japan. The findings reveal that more frequent physical exercise is associated with less psychological distress. Moreover, the data suggest that some (but not all) types of stressors tend to diminish the frequency of physical activity. Finally, and perhaps most important. the results reveal that social support tends to promote more frequent exercise. This can occur in two ways. First, more emotional support was related to better exercise habits. In addition, negative interaction was also associated with more frequent exercise, suggesting that informal social sanctions can foster positive health behaviors.
\end{abstract}

Key words - negative interaction, emotional support, physical exercise

An impressive array of studies suggest that stressful life events tend to depress daily mood and erode feelings of well-being in later life (see George [1] for a review of this research). However, this research has been conducted almost exclusively in Western countries, especially the United States. When establishing the relationship between two constructs, such as stress and well-being, careful consideration must be given to the external validity of the findings. This type of validity is concerned with the extent to which the results from a particular study can be generalized to other populations or to different settings. As Cook and Campbell [2] point out, a powerful factor for substantiating external validity is the replication of findings in distinct or divergent locations. Studies conducted in nonwestern countries may be especially useful in this respect because in no other way can we be certain that the findings observed in the United States are not merely the product of some complex set of historical, cultural, or political circumstances (see Kohn [3] for a detailed discussion of this issue).

The purpose of this study is to examine the relationship between stress and depressive symptoms with data obtained from a recent nationwide survey of older adults in Japan. However, instead of merely focusing on the direct effects of stress on well-being, an attempt will be made to capture some of the complexity of the stress process by assessing the ways in which Japanese elderly attempt to cope with the stressors that confront them. In particular, this study will examine the relationships among stress, social support, exercise, and depressive symptoms. The reasons for expanding the scope of the study in this manner are discussed below.

Although stress is generally thought to exert deleterious effects on well-being, many investigators believe that these negative sequalae can be offset or buffered by a number of social and psychological resources $[4,5]$. Considerable attention has been given in this respect to social support. This literature suggests that during stressful times, older adults with strong social support systems tend to experience fewer symptoms of psychological distress than elderly people who have less well-developed social support networks [6].

Much has been written about the strong social support networks in Japanese society $[7,8]$, but relatively few studies have systematically evaluated whether the Japanese actually turn to significant others for assistance during stressful times. This is especially true with respect to older adults in Japan. In fact, there seems to be some disagreement in the anthropological literature on whether the Japanese mobilize assistance from their social network members when they are confronted by stressful events. According to Lebra [7], Japanese people who are experiencing strain will not attempt to keep it to themselves but will instead feel compelled to discuss their problem with someone who will listen and understand. In contrast, Lock [9] maintairs that the traditional way to deal with problems in Japan is to repress one's feelings and to remain silent. Lock [9] argues that this behavior is based on the belief that it is inappropriate to analyze problems in human relations verbally because such scrutiny could disrupt harmonious social life. One goal of the present study is to empirically evaluate these competing points of view.

Even though research on social support has added greatly to our understanding of the stress process, a number of issues remain unanswered. Although there is considerable evidence that social support can help to reduce the undesirable impact of life stress, it is less 
clear how this effect takes place [10]. Research done largely with American subjects suggests that support may operate by bolstering feelings of control and well-being [1]. In order to expand the scope of this literature, an attempt will be made in the present study to examine another potentially important intervening mechanism that has been largely overlooked. even in studies of older adults in the United States. More specifically, we will test the hypothesis that support from significant others tends to offset the effects of stress in part because social network members may encourage older adults to engage in positive health behaviors, especially exercise. Establishing a link between social support and exercise is important because there is now considerable evidence that moderate levels of physical activity are associated with improved mood and enhanced feelings of well-being (for reviews of this research see Plante and Rodin [11] and Biddle and Fox [12]).

By incorporating exercise within the purview of this study, it is possible to make two contributions to the literature. First, while the impact of exercise on well-being has been assessed in a number of studies. few investigators have examined this relationship in conjunction with stress and social support. In addition, we have not been able to identify any studies that have examined the interface between stress, support, exercise, and well-being in Japan. It is important to examine these relationships in Japan because most research on stress and exercise has been conducted in the United States [13], and the bulk of this work has focused largely on white middle-class respondents [14].

There are at least two reasons why exercise and well-being may be related in samples of elderly Japanese. First, as Palmore and Maeda [8] point out, Japan is one of the few countries that has an estab- lished policy of promoting exercise among its senior citizens. As a result, elderly people in Japan may be aware of the beneficial effects of excrcise and more likely to participate in regular exercise regimens. Perhaps more important, evidence from anthropological studies suggests that the Japanese may be especially likely to turn to exercise as a way of coping with stressful events. More specifically, research by Lock [9] indicates that the Japanese frequently attempt to relieve tension by engaging in physical exercise or playing a musical instrument.

The discussion up to this point suggests that there is some justification for examining the relationship among stress, support, exercise, and well-being in Japan. However, this review has glossed over a number of important issues that have emerged from the burgeoning literature on stress and social support. A formal conceptual model was developed in order to incorporate some of the more recent developments in the stress field into this study. This conceptual framework will be introduced in the next section. Following this, the sample as well as the measures that are used to evaluate this model will be reviewed. Finally, findings are presented that emerge from estimating this model with data provided by a nationwide survey of older adults in Japan

\section{A CONCEPTLAL MODEL OF STRESS ANI WELL-BEING}

Figure 1 contains the conceptual model that is evaluated in this study. The notation used in this figure is consistent with the notation devised by Jöreskog and Sörbom [15]. It should be emphasized that the relationships among the constructs contained in this diagram were estimated after the effects of age, sex, and education had been controlled statistically.

The conceptual model contains a series of struc-

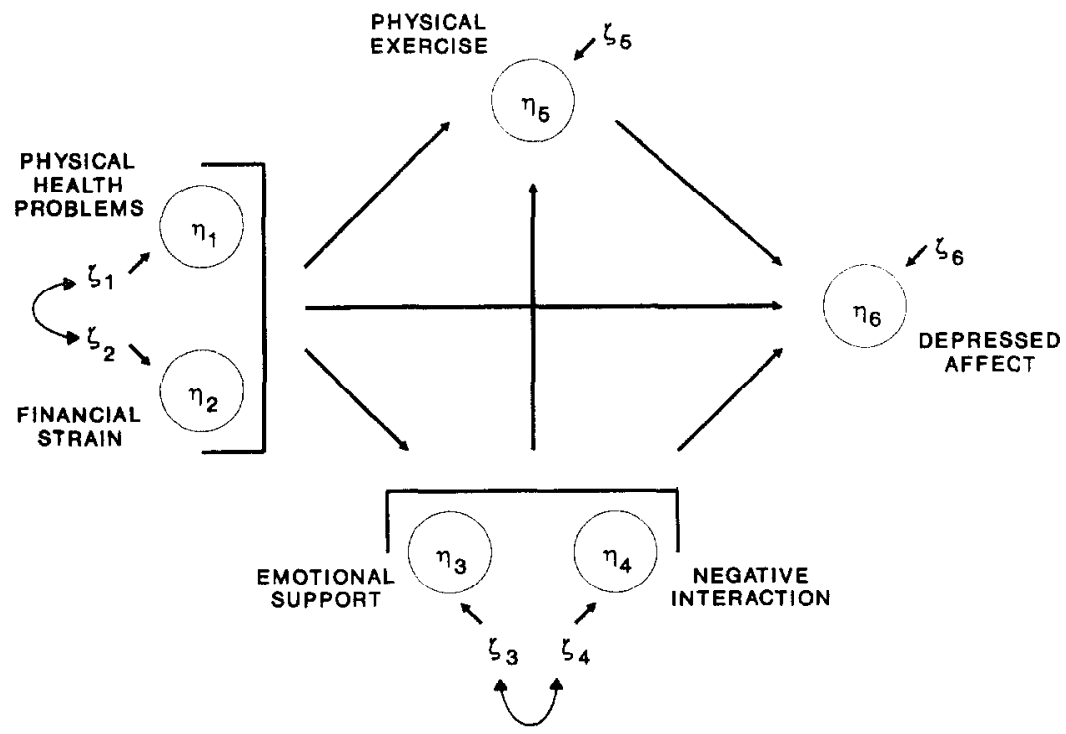

Fig. 1. A conceptual model of stress, social support, exercise and well-being. 
tural equations in which social support, exercise, and depressive affect symptoms serve as endogenous or dependent variables. The rationale for linking the independent variables with each of these outcome measures is presented below in order to facilitate the discussion of the complex relationships among these constructs.

\section{Stress and social support}

As the literature on the life stress process has evolved, researchers have begun to differentiate between different types of stressful experiences. One useful scheme contrasts stressful life events with chronic strains [16]. Essentially, these stressors are separated by a temporal distinction whereby stressful events are viewed as discrete time-bound experiences while chronic strains are thought to be continuous and ongoing. It is important to distinguish between stressful events and chronic strains because research indicates that chronic strains exert a more detrimental effect on well-being in later life than stressful events (see George [1] for a review of this research). Consistent with these research findings, two types of chronic strains are examined in this study: physical health problems $\left(\eta_{1}\right)$ and financial strain $\left(\eta_{2}\right)$. In addition, based on findings from American studies (to be discussed below), two latent constructs are also used to evaluate social support: emotional support $\left(\eta_{3}\right)$ and negative interaction $\left(\eta_{4}\right)$.

Research conducted in the United States suggests that illness and physical health problems represent one of the most frequently occurring stressors in later life [17]. The same also appears to be true in Japan, but research in this country has rarely examined physical health problems from a life stress perspective.

Research by Lebra [7] suggests that illness may serve an important function in Japanese society. She argues that illness provides an opportunity for emotional communication whereby the sick person draws the attention, sympathy, and support of his or her relatives and close friends. Some researchers use the concept of amae to explain this function [18]. Essentially, amae is an emotional state that is thought to permeate social relations in Japan. Amae involves a feeling of dependency that appeals to and is fulfilled by the indulgence of significant others. According to Lebra [7], sickness in Japan serves to gratify this dependency wish. Based on this research, it is hypothesized in Fig. 1 that as physical health problems $\left(\eta_{1}\right)$ increase, elderly Japanese respondents will report receiving more emotional support $\left(\eta_{3}\right)$ from their significant others.

Research on social support in the United States suggests that significant others can be a source of negative interaction as well as a source of support [19]. Unfortunately, less is known about support and negative interaction in Japan. In fact, it was primarily for this reason that a measure of negative interaction was incorporated into the conceptual model. Given the obligation of significant others to respond to the dependency wishes of sick people in Japan, it is hypothesized in Fig. I that as physical health problems $\left(\eta_{1}\right)$ increase, negative interaction $\left(\eta_{4}\right)$ from significant others will decline.

Taken together, the hypotheses introduced above are consistent with a resource mobilization perspective whereby individuals who are exposed to certain stressors (i.e. physical health problems) seek to marshall assistance from others. However, research conducted recently in the United State suggests that support mobilization is not a universal response to all stressors and that when certain stressors arise, older adults may avoid rather than seek out assistance from others [20]. Moreover, research suggests that social network members may even withdraw support when some (but not all) stressors occur [21]. It is particularly important to point out that the loss or withdrawal of support is especially likely to take place when financial difficulties arise.

There is some evidence that financial problems may have a similar effect on social support networks in Japan. Research by Lebra [7] suggests that the Japanese tend to view achievement and material success as a moral obligation. Moreover, failure in this realm may reflect poorly on one's group, leading individuals to believe that they have disgraced their significant others. These feelings of self-denigration may, in turn, lead to the avoidance (or withdrawal) of social support. Based on this rationale, it is predicted in Fig. 1 that as financial problems $\left(\eta_{2}\right)$ intensify, older adults in Japan will report receiving less emotional support $\left(\eta_{3}\right)$ from others.

Research by Lock [22] suggests that one of the most common sources of concern among the Japanese elderly is the fear of poverty and subsequent dependence upon their children. Moreover, there is some evidence that, contrary to popular beliefs, adult children in Japan may be ". . f far from pleased ..." about supporting their aging parents (Plath [23, p. 135]; see also Freed [24]). The fears of older adults, coupled with the resentment of their children, suggest that as financial problems $\left(\eta_{2}\right)$ increase, elderly people in Japan will report encountering more negative interaction $\left(\eta_{4}\right)$ with significant others.

\section{Physical exercise}

Although numerous studies have examined the effects of physical activity on well-being, less is known about the factors that influence the decision to maintain a program of regular exercise [25]. According to the model depicted in Fig. 1, physical exercise $\left(\eta_{s}\right)$ is thought to be affected by the interplay between stress $\left(\eta_{1}\right.$ and $\left.\eta_{2}\right)$ and social support $\left(\eta_{3}\right.$ and $\left.\eta_{4}\right)$.

Most of the research on stress and exercise focuses exclusively on the interaction effect between life stress and physical activity on feelings of well-being. By testing for interaction effects in this manner, many researchers overlook the possibility that stress may influence the ability or the willingness to engage in 
physical exercise. The model developed for the present study attempts to evaluate this assumption explicitly by testing for the direct effects of stress on physical activity.

There is some disagreement in the literature on the direction of the relationship between physical health problems and exercise. While most researchers maintain that people who exercise subsequently experience fewer health problems, a recent longitudinal study by Kaplan and his associates [26] indicates that an increase in physical health problems leads to diminished physical activity at a later point in time Although the relationship between these constructs is likely to be rcciprocal, we elected to test the specification shown in Fig. 1. More specifically, based on the work of Kaplan et al. [26], it is predicted that as the Japanese elderly encounter more physical health problem $\left(\eta_{1}\right)$ they will be less likely to engage in physical exercise $\left(\eta_{5}\right)$.

In contrast to physical health problems, it is further hypothesized in Fig. 1 that as financial strain $\left(\eta_{2}\right)$ increases. elderly pcople in Japan will report engaging in exercise more frequently $\left(\eta_{5}\right)$. This hypothesis is based on research by Lock [9] that was discussed carlier. It will be recalled that this work suggests that a common response to anxiety and frustration in Japan is involvement in physical activity.

Research by Cohen [27] and others indicates that the beneficial effects of social support may be attributed in part to the fact that significant others frequently offer encouragement to engage in positive health behaviors, including exercise, good dietary habits, and the responsible use (or avoidance) of akcohol and tobacco. The promotion of positive health behaviors by social network members constitutes an important link in our conceptual model. One contribution of this specification arises from the fact that the salubrious effects of supportive social relationships on exercise are viewed as arising in two ways. First. consistent with the observations of Cohen [27] and others, it is hypothesized that as the amount of emotional support $\left(\eta_{3}\right)$ provided by others increases, older adults in Japan will report engaging in physical exercise $\left(\eta_{5}\right)$ more frequently. In addition, it is further predicted that negative interaction $\left(\eta_{4}\right)$ will be associated with more physical exercise among the older adults in this country.

The heretofore largely overlooked link between negative interaction and exercise is based on the work of Rook. Thuras and Lewis [28], Hughes and Gove [29], and others. Although most investigators view negative interaction as having only undesirable consequences, Rook et al. [28] point out that significant others often perform a regulatory or social control function. The key point to emphasize is that often this regulatory function takes the form of criticism, social pressure, or some other form of negative interaction. That is, significant others may invoke informal sanctions (e.g. criticisms and demands) in order to get an individual to adopt positive health behaviors (see also
Umberson [30]). Even though the recipient may not appreciate the form that these negative communications take, the net effect may, nevertheless, be the promotion of positive health maintenance functions.

Although the theoretical perspective developed by Rook et al. [28] is intriguing, these investigators were unable to find empirical support for this view. However, a careful examination of their work suggests that they only examined the effects of social control on negative health behaviors, such as alcohol use. Another contribution of the present study arises from the fact that we attempt to establish a link between negative interaction and positive health behaviors as well

Much has been written about the high levels of social control in Japan and the pressure on the individual to conform to the will of the group (see, for example. Lebra [7]: Nakane [31]). If the rationale developed by Rook et al. [28] is valid and informal social control is a salient feature of Japanese society, then the relationship between negative interaction and exercise should be especially evident in the data that are used in the present study.

\section{Depressice symptoms}

According to the conceptual model, depressive affect symptoms $\left(\eta_{6}\right)$ are determined by physical health problems $\left(\eta_{1}\right)$, financial strain $\left(\eta_{2}\right)$, emotional support $\left(\eta_{3}\right)$, negative interaction $\left(\eta_{4}\right)$, and physical exercise $\left(\eta_{5}\right)$. The theoretical justification for proposing these linkages is provided below.

Literature reviewed by Plante and Rodin [11] as well as Biddle and Fox [12] suggests that physical activity appears to exert a beneficial effect on psychological well-being. There are a number of reasons why exercise and well-being may be related. For example, some investigators have identified a potentially important biological link whereby physical exercise results in the release of endorphins and other morphine-like substances in the body that can, in turn, elevate feelings of well-being. In contrast, other researchers argue that improved physical fitness serves to bolster key psychological resources, such as feelings of mastery and control. These findings are important because there is a vast literature which suggests that feelings of mastery and control are essential for the maintenance of psychological wellbeing in later life (for a review of this literature see Rodin, Timko and Harris [32]). Based on this research, it is hypothesized in Fig. 1 that as the level of physical activity $\left(\eta_{5}\right)$ increases, older adults in Japan will report experiencing fewer depressive affect symptoms $\left(\eta_{6}\right)$.

Earlier it was hypothesized that negative interaction would be associated with incrcased physical exercise. This hypothesis is designed to assess the regulatory or social control function of supportive social ties. However, as Hughes and Gove [29] point out, people may experience frustration, anger, and hostility when they are confronted by the regulatory 
efforts of others. These investigators propose that these negative emotions can subsequently promote psychological distress. Based on this theoretical rationale, it is hypothesized in Fig. 1 that as the amount of negative interaction $\left(\eta_{4}\right)$ increases, older adults in Japan will experience more depressive symptons $\left(\eta_{6}\right)$. Taken together, the relationships among negative interaction, exercise, and well-being suggest that the regulatory actions of others may have mixed effects and that social control can provoke psychological distress at the same time that it encourages the adaptation of positive health behaviors (i.e. exercise)

If intimate social relations in Japan are built upon the notion of amae and significant others indulge the deep-seated dependency wishes of others, then older adults in Japan should find the emotional support provided by their social network members to be especially gratifying. Consequently, it is hypothesized that as the amount of emotional support $\left(\eta_{3}\right)$ provided by others increases, elderly people in Japan will tend to experience fewer depressive symptoms $\left(\eta_{6}\right)$

Research conducted in the United States suggests that financial strain may have particularly noxious effects on well-being in later life [20]. It is especially important to note that the relationship between financial problems and well-being has been observed in different ethnic groups, including Mexican-Americans [33] and Black Americans [34]. Based on the findings in these studies, it is predicted in Fig. 1 that as financial problems $\left(\eta_{2}\right)$ intensify, older adults in Japan will tend to experience more psychological distress (i.e. depressive affect symptoms $-\eta_{6}$ ).

Finally, it is hypothesized in Fig. 1 that older adults in Japan who have physical health problems $\left(\eta_{1}\right)$ will report experiencing more depressive symptoms $\left(\eta_{6}\right)$ than elderly Japanese who enjoy better hcalth. This hypothesis is consistent with empirical as well as clinical work done in the United States which shows that the relationship between physical and mental health tends to be especially strong in later life (see Lurie [35] for a review of this research).

Having presented the theoretical justification for the linkages depicted in Fig. 1, it may be helpful to briefly describe how this conceptual scheme is estimated. The software program used in this study (i.e. Lisrel 7 [15]) utilizes full information estimation procedures. This means that the relationships among all of the constructs depicted in Fig. 1 are estimated simultaneously. So, for example, the software program estimates the impact of physical exercise on depressive symptoms at the same time that it estimates the relationship between financial strain and emotional support. By using all of the available information in this manner, the Lisrel 7 software program provides more precise estimates than conventional data analytic techniques, such as ordinary least squares (OLS) multiple regression analysis. The standard OLS approach involves estimating the relationships in each equation separately. In effect, these coefficients are computed without knowing what is going on elsewhere in the model. A more detailed discussion of the benefits derived from the use of full information estimation procedures is provided by Bollen [36].

\section{METHODS}

\section{Sample}

The data for this study come from a random-probability sample of 2200 persons in Japan who were at least 60 years of age at the time of the interview. This nationwide study, which was conducted in 1987, was based on a two-stage probability sampling design. In the first stage, census tracts were stratified according to geographic region (11 regions were specified for this purpose) and city size ( 5 categories were designated ranging from 11 major metropolitan areas to small villages or towns). A stratified sample of 192 primary sampling units (PSUs) was selected with probability proportionate to size. After a random start, the PSUs were selected within each strata using an equal-interval method. In the second stage of the sampling strategy, respondents were selected at random within each PSU, again using an equal-interval method. Overall, an average of 15 older adults were selected from each PSU (minimum $=8$, maximum $=16$ ). The names of potential study participants were obtained from the Resident Registries, which contain an up-to-date listing of the names, addresses, sex, and age of all Japanese citizens.

The overall response rate for the survey was $69 \%$. The average interview lasted $59 \mathrm{~min}$. After eliminating cases containing missing values with listwise deletion procedures, a total of 1351 cases were availablc for analysis. The average age of the people in this group was 68.7 years ( $\mathrm{SD}=6.6$ years). Overall, $49 \%$ of the study participants were men. Finally, the respondents reported that they had completed an average of 8.8 years of formal education $(\mathrm{SD}=2.9$ years).

As the description of the study sample reveals, there are two reasons why all of the potential subjects are not included in the analyses presented below. First, some subjects did not participate in the study. This occurred for a variety of reasons. For example, some elderly people refused to be interviewed; others were never contacted because they could not be found at home after repeated calls; while other older adults were too ill to participate in the survey. Loss of data for these reasons is referred to in the literature as unit nonresponse. In contrast to this problem, some elderly people participated in the study, but complete information on all study measures is not available for these individuals. This problem typically arises because some people are unable or unwilling to answer a particular question (thereby generating a "don't know" response) or because interviewers inadvertently forget to ask a question. It is important to determine whether unit and item nonresponse occur 
Table 1. Preliminary analysis of missing values

\begin{tabular}{|c|c|c|c|}
\hline \multirow[b]{2}{*}{ Variable } & \multirow{2}{*}{$\begin{array}{l}\text { Mean for cases in } \\
\text { structura! model } \\
\quad(N=1351)\end{array}$} & \multicolumn{2}{|c|}{ Mean for cases } \\
\hline & & $\begin{array}{l}\text { excluded from } \\
\text { the model }\end{array}$ & $\begin{array}{l}T \text {-test for } \\
\text { mean differences }\end{array}$ \\
\hline Age & 68.715 & 69.870 & $P<0.001$ \\
\hline Sex & $1.50 x$ & 1.611 & $p<0.001$ \\
\hline Education & 8.779 & 8.391 & $P<0.01$ \\
\hline Physical problems & 6.421 & 6.936 & $P<0.001$ \\
\hline Financial strain & 6.349 & 6.908 & $\rho<0.001$ \\
\hline Emotional support & 8.394 & 8.115 & $P<0.01$ \\
\hline Negative interaction & 6.392 & 5.842 & $P<0.001$ \\
\hline Physical exercise & 8.540 & 7.948 & $P<0.001$ \\
\hline Depressive symploms & 3.277 & 3.422 & $P<0.001$ \\
\hline
\end{tabular}

randomly because a systematic loss of data for certain kinds of respondents can bias study findings. The preliminary analyses that were designed to explore this issue are reviewed briefly below.

It is usually difficult to evaluate patterns of unit nonresponse in survey research because investigators often have little or no information about the people who did not participate. However, as discussed above, the sample for the present study was obtained from the Japanese Resident Registries. Consequently, we were able to get information on the age, sex, geographic region, and degree of urbanicity for all individuals who did not take part in the survey. This information makes it possible to determine whether there are significant differences between responders and nonresponders on each of these demographic indicators. The results of the extensive analyses that were conducted to examine this issue are reported elsewhere [37]. Essentially, the results revealed that men were more likely to be nonresponders than women and that rates of unit nonresponse were highest in large urban areas. In addition, a curvilinear relationship between age and response status emerged with nonresponse being higher in the younger and oldest age groups. Finally, the rate of unit nonresponse was higher in some geographic regions, especially those areas where the cities of Tokyo and Osaka are located.

It is not possible to determine the extent to which the nonrandom pattern of unit nonresponse described above influenced the substantive finding in this study. Nevertheless, this potential source of bias should be kept in mind as the results from this study are reviewed.

Compared to the analyses presented above, it is somewhat easier to evaluate the effects of item nonresponse because more information is available. We performed a series of $t$-tests to compare the means on all study meaures for cases included in the main analyses $(N=1351)$ with the corresponding means for those cases that were excluded because they contained missing values.

The nature of the data in the second group described above requires further clarification. Cases were eliminated from the analyses if they contained missing values on any one of the study measures. It is important to point out. however, that even though a case has been excluded, it still may contain valid data on one or more of the remaining study measures. This means, for example, that a case may have a missing value on the depressive symptom measure but still have valid responses for the emotional support or negative interaction items. These valid responses were used to compute the means for the second group in order to perform the $t$-tests described above.

The results of the $t$-tests are presented in Table 1 . Although a more detailed description of the study measures will be provided later, it is necessary to briefly identify how the measures are coded so that the results contained in Table 1 can be interpreted properly. A high score on the variable assessing gender denotes women while a high score on the education measure reflects more years of completed schooling. Moreover, a high score represents more physical health problems, greater financial difficulty, more emotional support, more negative interaction, more frequent exercise, and more depressive symptoms.

The data in Table I suggest that item nonresponse was more likely to occur among subjects who are older, female, and less educated. Moreover, respondents who were excluded from the analyses reported experiencing more physical health problems and greater financial strain. The $t$-tests further revealed that those older adults who were eliminated from the analyses reccived less emotional support and encountered more negative interaction with others. Finally, the data in Table 1 suggest that subjects who were excluded from the study tended to exercise less frequently and experience more depressive symptoms. Taken as a whole the results presented in Table 1 indicate that item nonresponse occurred in a systematic fashion. Although we cannot tell whether these mean differences affected the relationships among the study measures (i.e. the coefficients in the structural equation model), the potential problems created by item nonresponse should be kept in mind as the findings from this study are reviewed. 


\section{Measures}

Table 2 contains a listing of the observed indicators that were used to measure the latent constructs depicted in Fig. 1. In addition, this table also contains the factor loadings and measurement error terms that were generated with the Lisrel 7 statistical software program [15].

The information furnished by the measurement model parameter estimates is important because it provides some preliminary insights into the psychometric adequacy of the observed indicators used in this study. The factor loadings are especially useful in this respect. Although there are no firm guidelines in the literature, researchers tend to agree that factor loadings in excess of 0.400 suggest that an observed indicator is a good measure of the latent construct it is thought to represent (see, for example, Liang [38]). The factor loadings listed in Table 1 range from 0.458 to 0.890 , suggesting that the measures used in this study have acceptable psychometric properties.

Physical health problems. As shown in Table 2, perceived physical health problems are assessed with three observed indicators. These items ask respondents how they would rate their overall health status; how they would compare their health to that of other older adults; and whether they are satisfied with their health.

Table 2. Study measures

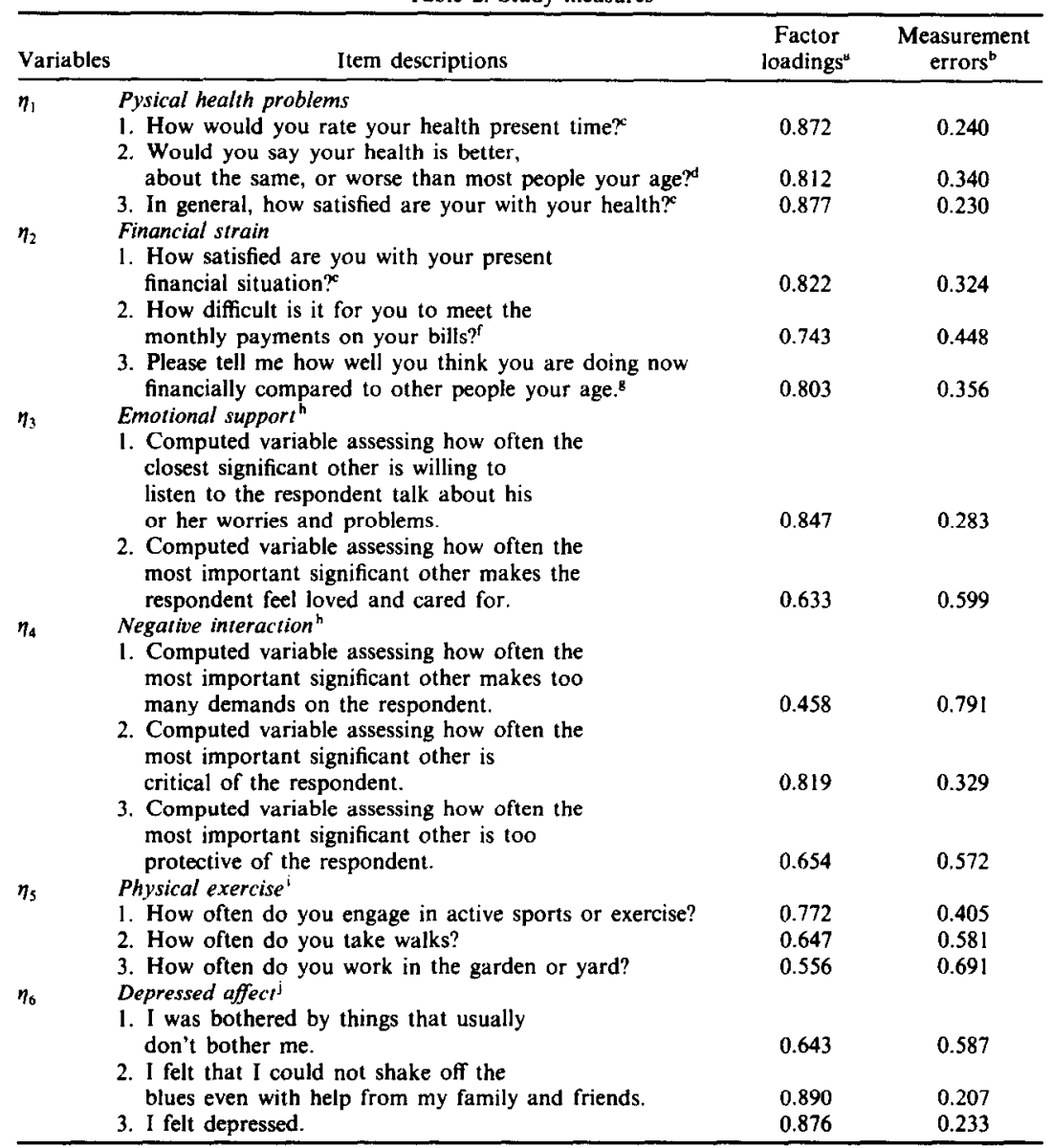

"Standardized factor loading. The first-listed item for each latent construct was constrained to 1.0 in the unstandardized solution.

'The measurement error estimates are from the standardized solution.

'This item was scored in the following manner (coding in parentheses): poor (5); fair (4); good (3); very good (2); excellent (1)

This item was scored in the following manner: worse (3); about the same (2); better (1)

'These items were scored in the following manner: not at all satisfied (5); not very satisfied (4); somewhat satisfied (3); very satisfied (2); completely satisfied (1).

'This item was scored in the following manner: extremely difficult (5); very difficult (4); somewhat difficult (3); slightly difficult (2); not at all difficult (1).

'This item was scored in the following manner: worse (3); about the same (2); better (1)

${ }^{h}$ These items were scored in the following manner: a great deal (5); quite a bit (4); some (3); a little (2); not at all (1).

'These items were scored in the following manner; often (4); sometimes (3); rarely (2); never (1).

'These items were scored in the following manner: most of the time (3); some of the time (2); hardly ever (1). 
There is considerable debate in the literature about the nature and meaning of the underlying construct that is measured by the physical health items contained in Table 1 [39]. Although researchers have used these indicators as proxy measures of objective health status, it is evident that these perceived health measures contain not one, but at least two components: health problems as well as perceptions or judgements about the severity of these conditions. It is important to review why these perceptual measures were selected for use in this study,

Earlier, we argued that physical health problems would tend to discourage older adults from engaging in exercise. The decision not to engage in physical activity clearly cannot take place unless older adults believe that they have health problems and they judge these problems to be serious. In order to evaluate this theoretical orientation fully, it is important to utilize measures that assess perceptions or evaluations of health problems.

Financial strain. Three observed indicators were also used to assess financial problems. These items evaluate whether respondents are satisfied with their financial situation, whether they have trouble paying their monthly bills, and how their financial situation compares with that of other elderly people.

Emotional support. A measure of emotional support was computed from a series of items that were contained in the interview schedule. Initially, study participants were asked to indicate how much emotional support they had received from each of three separate sources: one's spouse, children and grandchildren (combined), and all other (i.e. all other relatives and friends combined). Information on support was gathered in this manner because research indicates that the amount of assistance as well as the way in which support is evaluated may depend upon the nature of the relationship between the provider and recipient [40].

Although information on the amount of support that is provided by specific sources is useful, this measurement strategy tends to create data analytic problems. Essentially, it is difficult to create summary social support scores for respondents in large-scale community surveys because all individuals do not (or cannot) receive assistance from the same sources. An example may help to clarify the nature of this problem. A significant number of the participants in this study are widows. Obviously, it is not possible to ask these people about the amount of support they have received from their spouse. Similarly, the respondents did not all have children or grandchildren. This creates problems because there is no easy way to compare older adults who have reccived support from others only with elderly people who have received assistance from their spouse, children, grandchildren, as well as from others. In essence, the amount of support becomes confounded with the number of individuals who have given assistance (see
Wortman and Dunkel-Schetter [41] for a detailed discussion of this problem).

There are at least two ways to resolve this dilemma. The first involves estimating the model shown in Fig. 1 within subgroups of respondents who have all received support from the same sources. This means, for example, that one set of analyses would be performed for persons receiving assistance from their spouse, children and grandchildren, and others, while a separate set of analyses would be conducted for those individuals receiving support from others only. We have used this strategy in analyzing comparable data gathered in the United States, but we have found that this approach leads to a lengthy and complicated set of analyses [21].

An alternative approach is to identify the one source that provides the most assistance from among all of the sources available to a study participant. This would result in a social support score that could be compared across all respondents because each individual can have one and only one best source of assistance.

The alternative described above was used in the present study. A question was embedded in the received emotional support items that asked study participants to identify the person who was most willing to listen to them talk about their problems and worries. The individual identified in this item was subsequently used to select an emotional support score from among all of the sources available to the respondent. So, for example, if a woman indicated that her husband was most likely to listen to her talk about her worries and problems, then her emotional support score was based solely on the amount of assistance provided by her spouse. In effect, this derived measure reflects the amount of emotional support provided by the most important or closest significant other.

Although this alternative coding procedure helps to resolve a technical data analytic dilemma, it is important to clearly delineate the theoretical implications of using this measurement strategy. A key theoretical premise in this study is that the support and social regulation provided by significant others tends to increase the probability that older adults will engage in physical activity. According to Rook et al. [28], not all significant others perform this regulatory function. Instead, attempts to regulate the behavior of older adults tend to arise only within the context of close relationships that entail enduring responsibilities and obligations. It is only under these circumstances that attempts at behavioral regulation will be viewed as legitimate.

Research reviewed by Barnlund [42] suggests that the Japancse tend to have fewer casual associates than Americans. According to Barnlund [42], this is due to the fact that the Japanese prefer to avoid getting enmeshed in the more stringent duties and obligations that are expected in social relationships in their country. However, this literature further 
suggests that the Japanese are more deeply committed to the few close ties that they elect to maintain. If social regulation is most likely to arise within the context of intimate relationships and the Japanese are more committed to their close associates, then the relationship between emotional support and exercise should be especially evident when measures of support provided by the closest significant other are used in the analyses.

Negative interaction. As shown in Table 2, negative interaction is measured with three observed indicators. Following the rationale and procedures described in the previous section, this measure reflects the amount of negative interaction that is encountered with the person that is closest to the respondent. That is, the same source is used for computing negative interaction as well as emotional support scores. This coding procedure is justified because research in the United States suggests that negative interaction is especially likely to arise within the context of close relationships [19].

Physical exercise. Physical activity is assessed with three observed indicators. As shown in Table 2, these items measure how often Japanese elderly engage in sports, take walks, or work in the garden.

Depressed affect. Factor analytic work with depressive symptom scales typically reveals that these indices contain at least three clusters of items [43]. The first cluster, which is usually referred to as depressive affect symptoms, reflects the cognitive aspects of depression, such as feeling sad or blue. The second cluster or factor that usually emerges in these studies (i.e. somatic symptoms) represents the physiological manifestations of psychological distress, including appetite loss and problems with sleeping. The final factor reflects interpersonal difficulties and assesses feelings of being rejected by others.

Measures of all three depressive symptom factors were available in this study. These observed indicators were taken from the Center for Epidemiologic Studies Depression Scale [44]. However, we decided to use only the depressive affect items. The somatic symptom items were excluded because we felt that they would be confounded with the measure of physical health problems. Similarly, the interpersonal difficulties items were eliminated because they may be confounded with social support (especially negative interaction).

Demographic control measures. As discussed earlier, the effects of three demographic control variables (age, sex and education) were taken into account when the model in Fig. 1 was estimated. These measures were included in the model to control for the effects of population heterogeneity. It should be emphasized, however, that the relationship between these demographic measures and the constructs contained in the model have been of considerable theoretical interest to some investigators. Nevertheless, we did not develop specific hypotheses in this study for the effects of the demographic measures because we wanted to avoid developing a conceptual framework that is unwieldy and difficult to present.

Age is coded in a continuous format. As discussed above, education reflects the total number of years of completed schooling. Finally, sex is measured with a binary variable where a score of two is assigned to women and a score of one is given to men.

\section{RESULTS}

Preliminary data analysis (not shown here) revealed that some of the items listed in Table 2 are highly skewed (e.g. the depressive symptom items). This suggests that the assumption of multivariate normality may be violated if these indicators are used to estimate the model depicted in Fig. 1. Although there is some debate about the implications of violating this assumption, the prevailing view is that the use of skewed indicators can bias tests of statistical significance as well as the estimates derived with goodness-of-fit indices (see for example Huba and Harlow [45]).

Fortunately, the Lisrel 7 statistical software program contains an estimation procedure that does not assume that the observed indicators are distributed normally. This estimation method, weighted least squares, was used to evaluate the model depicted in Fig. 1 (see Jöreskog and Sörbom [15] for a detailed discussion of this distrubtion-free estimation procedure). Following procedures described by Jöreskog and Sörbom [15], two special input matrices were created for use with this program; an asymptotic covariance matrix and a matrix containing polyserial, polychoric, and Pearson correlation coefficients.

Table 3 contains the results that were derived from estimating the conceptual model. Before turning to the substantive findings in this table it is important to first examine the fit of the model of the data.

Estimates provided by several goodness-of-fit indices are presented in the first footnote in Table 3. Taken together, these estimates suggest that the fit of the hypothesized model to the data is adequate. This can be seen, for example, in the derived AGFI value (0.982). Although a minimum acceptable cutpoint score has not been identified for this measure, experience suggests that values in excess of 0.900 are acceptable (see Jöreskog and Sörbom [15] for a detailed discussion of this index). Similarly, the value obtained with the Bentler-Bonett [46] normed fit index $(0.971)$ exceeds the recommended minimum value of 0.900 . Finally, the estimate provided by Bollen's [36] nonnormed fit index (0.985) is quite close to the ideal value of 1.0 .

The model developed for this study is rather complex and contains a number of hypothesized linkages. In order to present the substantive findings in a more comprehensible manner, the results will be reviewed in three sections. First, the impact of financial strain and physical health problems on social support will be examined. Following this, estimates of the 
Table 3. Stress and depressive symptoms among the Japanese elderly $(N=1351)^{\mathrm{a}}$

\begin{tabular}{|c|c|c|c|c|c|c|}
\hline \multirow[b]{2}{*}{$\begin{array}{l}\text { Independent } \\
\text { variables }\end{array}$} & \multirow[b]{2}{*}{$\begin{array}{c}\text { Physical } \\
\text { problems }\end{array}$} & \multicolumn{4}{|c|}{ Dependent variables } & \multirow[b]{2}{*}{$\begin{array}{c}\text { Depressed } \\
\text { affect }\end{array}$} \\
\hline & & $\begin{array}{l}\text { Financial } \\
\text { problems }\end{array}$ & $\begin{array}{l}\text { Emotional } \\
\text { support }\end{array}$ & $\begin{array}{c}\text { Negative } \\
\text { interaction }\end{array}$ & $\begin{array}{l}\text { Physical } \\
\text { exercise }\end{array}$ & \\
\hline Age & $\begin{array}{c}-0.001^{b} \\
(-0.001)^{c}\end{array}$ & $\begin{array}{c}-0.043 \\
(-0.036)\end{array}$ & $\begin{array}{c}-0.019 \\
(-0.016)\end{array}$ & $\begin{array}{c}-0.039 \\
(-0.018)\end{array}$ & $\begin{array}{c}0.009 \\
(0.005)\end{array}$ & $\begin{array}{c}0.017 \\
(0.011)\end{array}$ \\
\hline Sex & $\begin{array}{l}0.137^{* * *} \\
(0.120)\end{array}$ & $\begin{array}{r}0.081^{*} \\
(-0.066)\end{array}$ & $\begin{array}{l}-0.160^{* * *} \\
(-0.135)\end{array}$ & $\begin{array}{l}-0.237^{* * *} \\
(-0.108)\end{array}$ & $\begin{array}{c}0.025 \\
(0.014)\end{array}$ & $\begin{array}{l}0.166^{* *} \\
(0.107)\end{array}$ \\
\hline Education & $\begin{array}{c}-0.030 \\
(-0.026)\end{array}$ & $\begin{array}{l}-0.110^{* * *} \\
(-0.090)\end{array}$ & $\begin{array}{c}-0.056 \\
(-0.047)\end{array}$ & $\begin{array}{c}-0.042 \\
(-0.019)\end{array}$ & $\begin{array}{c}0.089^{*} \\
(0.050)\end{array}$ & $\begin{array}{c}0.065 \\
(0.041)\end{array}$ \\
\hline Physical problems & & & $\begin{array}{c}0.033 \\
(0.032)\end{array}$ & $\begin{array}{c}-0.066^{* *} \\
(-0.035)\end{array}$ & $\begin{array}{l}-0.419^{* * *} \\
(-0.267)\end{array}$ & $\begin{array}{l}0.238^{* * *} \\
(0.176)\end{array}$ \\
\hline Financial strain & & & $\begin{array}{l}-0.265^{* * *} \\
(-0.273)\end{array}$ & $\begin{array}{l}0.207^{* * *} \\
(0.115)\end{array}$ & $\begin{array}{c}-0.306 \\
(-0.024)\end{array}$ & $\begin{array}{c}0.104^{*} \\
(0.081)\end{array}$ \\
\hline Emotional support & & & & & $\begin{array}{l}0.152^{* * *} \\
(0.100)\end{array}$ & $\begin{array}{c}0.039 \\
(0.030)\end{array}$ \\
\hline Negative interaction & & & & & $\begin{array}{l}0.131^{* * *} \\
(0.159)\end{array}$ & $\begin{array}{l}0.248^{* * *} \\
(0.349)\end{array}$ \\
\hline Physical exercise & & & & & & $\begin{array}{l}-0.160^{* *} \\
(-0.185)\end{array}$ \\
\hline
\end{tabular}

The fit of the model to the data is: $\chi^{2}=272.45$ with $137 d f ; \mathrm{GFI}=0.988 ;$ AGFI $=0.982 ;$ Bentler-Bonett $\Delta=0.971$; Bollen nonnormed $\Delta=0.985$.

${ }^{\mathrm{b}} \mathrm{Standardized}$ regression coefficient.

Metric (unstandardized) regression coefficient

$* P<0.05 ; * * P<0.01 ; * * P<0.001$.

relationships among stress, social support, and exercise will be presented. Finally, the impact of the variables shown in Fig. 1 on depressive symptoms will be reviewed.

Stress and support mobilization. The data in Table 3 suggest that stress can affect the amount of support received by elderly people in Japan, but that the specific type of stressor must be taken into consideration when the relationship between these constructs is examined. While greater financial strain is associated with less emotional support $(\beta=-0.265$; $P<0.001)$ and more negative interaction $(\beta=0.207$; $P<0.001$ ), physical health problems do not appear to exert similar effects. Instead, greater health difficulties are related to less negative interaction ( $\beta=-0.066 ; P<0.01$ ). However, it is evident that this effect is fairly modest. Moreover, the data fail to confirm the hypothesized relationship between physical health problem and emotional support ( $\beta=0.033$; not significant).

Given the purported use of the sick role in Japan for eliciting attention and sympathy from others, the failure to observe a significant relationship between physical health problems and emotional support is puzzling. Perhaps part of the explanation may be found in the way we measured social support. The measure used in this study emphasizes the verbal communication of emotional support (e.g. how often someone listens to the respondent talk about his or her problems). However, research reviewed by Barnlund [42] suggests that the Japanese hold verbal communication in relatively low esteem and instead have greater respect for nonverbal forms of communication. Perhaps a significant relationship between physical health problems and emotional support would have emerged from the data had a measure of nonverbal emotional support been available.
Stress, social support and exercise. One of the major goals of this study is to examine whether significant others influence the exercise habits of elderly people in Japan. The data in Table 3 tend to support the hypothesized relationships between these constructs. More specifically, greater emotional support is associated with more frequent exercise $(\beta=0.152$; $P<0.001)$. Moreover, consistent with the social regulatory hypothesis derived by Rook et al. [28], more negative interaction is related to more physical activity among the Japanese elderly $(\beta=0.131$; $P<0.001$ ).

The findings with respect to stress and exercise are less consistent. As hypothesized, more health problems are associated with less physical exercise ( $\beta=-0.419 ; P<0.001)$, but financial problems do not appear to exert a significant effect on physical activity $(\beta=-0.036$; not significant). These results indicate that the Japanese elderly do not necessarily attempt to cope with all types of stress by exercising. Clearly, the potential coping functions of exercise need to be examined across a wider range of stressful experiences than are included in our study.

Correlates of depressive symptomatology. A second major goal of this study is to test the hypothesis that exercise is related to psychological distress among the Japanese elderly. The data in Table 3 tend to support this view. These findings reveal that more frequent exercise is associated with fewer depressive affect symptoms $(\beta=-0.160 ; P<0.01)$. This is the first study that we could find in the English literature that documents the beneficial effects of exercise on wellbeing among older adults in Japan.

Returning to Table 3 , the findings show that more negative interaction is related to greater psychological distress $(\beta=0.248 ; P<0.001)$. However, in order to understand the relationship between negative interaction and distress more fully, this finding needs 
to be viewed in conjunction with the results that have been reviewed up to this point. Although negative interaction tends to have a positive direct effect on psychological distress, the findings reviewed above suggest that negative social encounters may also serve to reduce distress indirectly by encouraging older adults to engage in physical exercise. Taken together, these results appear to support the observations of Hughes and Gove [29], who argue that while social control may encourage positive health behaviors, the regulatory actions of others can also create psychological distress.

One advantage of the data analytic approach used in our study is that it is possible to quantify the dual functions of negative interaction. This makes it possible to identify the extent to which the health promotion function of negative interaction offsets the harmful direct effects of negative social encounters on well-being. To the best of our knowledge, this type of analysis has not been performed previously, even in studies conducted in the United States. These empirical insights are provided by examining the direct, indirect, and total effects of negative interaction on depressed affect scores. Recent developments in the Lisrel 7 statistical software program make it possible to compute these effects and to derive tests of statistical significance for these parameter estimates (see Jöreskog and Sörbom [15] for a detailed discussion of these procedures).

Further data analysis (not shown in Table 3) suggests that the indirect effect of negative interaction on depressive symptoms that operates through physical exercise is statistically significant. However, the size of this effect is fairly modest $(\beta=-0.021$; $P<0.05$ ). When this indirect effect is added to the direct effect of negative interaction on well-being $(\beta=0.248)$, the resulting total effect is positive and fairly large $(\beta=0.227 ; P<0.05)$. This coefficient suggests that even though negative interaction can reduce psychological distress indirectly, these advantages are far outweighed by the harmful direct effects of negative encounters with significant others.

Earlier, we hypothesized that emotional support would tend to reduce feelings of distress among the Japanese elderly. The data in Table 3 fail to support this hypothesis ( $\beta=0.039$; not significant). Although emotional support is associated with more frequent exercise, and more physical activity tends to reduce depressive symptoms, the magnitude of this indirect effect is quite small $(\beta=-0.025 ; P<0.05 ;$ not shown in Table 3). Even though the reason for this finding is not clear, the results are consistent with studies in the United States which show that negative interaction is a more important determinant of wellbeing in later life than positive social support [19].

Returning to Table 3 , the data reveal that, as predicted, greater physical health problems are associated with more depressive affect symptoms $(\beta=0.238 ; P<0.001)$. Similarly, as financial problems intensify, older adults in Japan tend to experi- ence more symptoms of distress $(\beta=0.104$; $P<0.05)$. The effects of financial strain on depressive symptoms appear to be smaller than comparable effects reported in studies conducted in the United States [20,33]. Greater insight into this discrepancy can be found by examining the indirect and total effects of financial strain that operate through social support and exercise.

Further data analysis (not shown in Table 3) indicates that the indirect effects of financial strain on depressive symptoms that operate through support and exercise are statistically significant $(\beta=0.049$; $P<0.05$ ). When these indirect effects are added to the direct effect shown in Table 3 , the resulting total effect is also statistically significant $(\beta=0.153$; $P<0.05$ ). Decomposing the effects in this manner suggests that financial problems tend to promote psychological distress and that approximately onethird of this effect may be attributed to the fact that financial problems tend to decrease social support and discourage physical activity.

Taken together, the findings presented in this section suggest that examining the interplay between stress, social support, and exercise can provide useful insights into the factors that affect psychological distress among older adults in Japan. In fact, the variables contained in Fig. 1 explain approximately $21 \%$ of the variance in depressive symptom scores for older adults in that country.

\section{DISCUSSION}

The findings that have emerged from this study serve to both corroborate and extend research that has been conducted in Western countries. Consistent with research in the United States, these results confirm that stress can affect the amount of support provided by significant others, and that certain stressors can actually serve to reduce the amount of assistance received from social network members. The results from our study also affirm findings from American research which suggest that exercise exerts a beneficial effect on well-being in later life. Finally, the data reviewed above suggest that, as in the United States, negative interaction is associated with increased psychological distress. To the best of our knowledge, this is the first time that these relationships have been examined with a sample consisting of older adults in Japan. By confirming these observations in a diverse cultural setting, this study serves to enhance the external validity of research on stress and well-being in Western countries.

In addition to replicating the results of other investigators, our study also helps to extend work on the stress process by integrating measures of stress, social support, exercise, and psychological distress into the same conceptual framework. In particular, the findings reviewed above suggest that some (but not all) stressors may affect the ability or willingness to engage in physical exercise. Perhaps more import- 
ant, the results help to establish a link between social support and exercise, thereby providing further insights into how the beneficial effects of supportive social relationships may emerge in later life. More specifically, the analyses revealed that social support can affect exercise in at least two ways. First, the findings suggest that greater emotional support may be associated with more frequent exercise. In addition, the results indicate that negative interaction may also be related to increases in physical exercise. This latter finding is especially important because it serves to highlight the social regulatory function of negative interaction. Although a number of $\Lambda$ meri can investigators have proposed that social sanctions tend to promote positive health behaviors, they have been unable to find empirical support for their views $[28,29]$. Research in Western countries has focused largely on the undesirable properties of negative social interaction. By identifying the potential positive functions of this type of social encounter, we hope to create a more balanced view of the role of negative interaction in later life. The challenge now is to see whether the findings that have been observed in Japan can be replicated with comparable data in the Western countries.

It is important to discuss the limitations in this study so that the findings may be placed in a proper perspective. There are at least four shortcomings in the research presented above: the data are cross-sectional; only two types of stress were included in the conceptual model; the analyses were performed with global social support measures; and, only one type of positive health behavior was examined. These limilations are reviewed briefly below.

The data used in this study were gathered at one point in time. Consequently, the temporal ordering among the constructs contained in Fig. 1 was based on theoretical considerations alone. It is entirely possible, however, to specify a different causal sequence among these latent variables. For example, we have proposed that physical exercise tends to enhance feelings of well-being. Although previous work suggests that this is a plausible assumption, we cannot rule out the possibility that older adults who are suffering from depressive symptoms may subsequently decide not to exercise. Clearly, this as well as other causal assumptions that are embedded in Fig. 1 need to be subjected to rigorous empirical analysis with longitudinal data.

Our study looks only at the effects of physical and financial problems. Although these stressors are encountered frequently in later life, they obviously do not represent the only types of problems that are experienced by older adults. Additional research is needed to evaluate how other types of stressors (e.g. bereavement and stressful events occurring to significant others) can affect social support and exercise.

Only global measures of social support were available for this study. This means, for example, that the items assess how often significant others make de- mands on a study participant without specifying the precise nature of these demands. A more direct test of the social regulation hypothesis proposed by Rook et al. [28] calls for more focused measures that explicitly ask whether social network members insisted that study participants engage in physical exercise.

Finally, our conceptual model was concerned with the effects of social support on only one specific type of health behavior (i.e. exercise). Research is needed to document the role that social support systems play in establishing other positive health behaviors, such as good dietary habits as well as the proper use of medications.

In view of these limitations, it should be evident that the model used in this study represents a preliminary attempt to capture a complex process and that this conceptual framework is in need of further development. For example, it may be especially useful to test for subgroup differences in the model. More specifically, the relationships among stress, social support, exercise, and well-being may vary by gender. urbanicity (i.e. whether a respondent lives in an urban or rural area), and employment status. It is important to continue work in this field because while the beneficial effects of supportive social relationships are now fairly well documented, very little is known about how these salutary effects accrue. We believe that the research presented above takes a modest, but fruitful step toward the identification of these critical intervening mechanisms.

Acknowledgements - Support for this research was provided under the following grants from the National Institute of Aging: ROI AG08491 (Principal Investigator-Neal Krause); R37 AG06643 (Principal Investigator-Jersey Liang); and T32 AG00114.

\section{REFERENCES}

1. George L. K. Stress, social support, and depression over the life course. In Aging, Stress, Social Support and Health (Edited by Markides K. S. and Cooper C. L.). p. 241. Wiley, Chester, 1989.

2. Cook T. D. and Campbell D. T. The design and conduct of quasi-experiments and true experiments in field settings. In Handbook of Industrial and Organizational Psychology (Edited by Dumnette M. D.), p. 223. Rand McNally, New York, 1987.

3. Kohn M. L. Cross-national research as an analytical strategy. Am. Sociol. Rev. 52, 713, 1987

4. Cohen S. and Edwards J. R. Personality characteristics as moderators of the relationship between stress and disorder. In Advances in the Investigation of Psychological Stress (Edited by Neufeld R. W.), p. 235. Wiley, New York, 1989.

5. Krause $\mathrm{N}$. Issues of measurement and analysis in studies of social support, aging, and health. In Aging, Siress, Social Support and Health (Edited by Markides K. S. and Cooper C. L.), p. 43. Wiley, Chester, 1989.

6. Krause N. Life stress, social support, and self-esteem in an elderly population. Psychol. Aging 2, 349. 1987.

7. Lebra T. S. Japanese Patterns of Behavior. University of Hawaii Press, Honolulu, 1976 
8. Palmore E. B. and Maeda D. The Honourable Elders Revisited: A Revised Cross-Cultural Analysis of Aging in Japan. Duke University Press, Durham, NC, 1985

9. Lock M. Popular conceptions of mental health in Japan. In Cultural Conceptions of Mental Health and Therapy (Edited by Marsall A. J. and White G. M.), p. 215. D. Reidel, Boston, 1982.

10. Krause N. Stress, social support, and well-being: Focusing on salient social roles. In Stress and Coping in Later Life Families (Edited by Stephens M. A. et al.), p. 71 . Hemisphere, Washington, DC, 1990.

11. Plante T. G. and Rodin J. Physical fitness and enhanced psychological health. Curr. Psychol. Res. Rev. 9, 3, 1990.

12. Biddle S. J. and Fox K. R. Exercise and health psychology: Emerging relationships. $\mathrm{Br} . J$. med. Psychol. 62 , 205, 1989.

13. Dudda J. L. and Allison M. T. Cross-cultural analysis in exercise and sport psychology: A void in the field. J. Sport exercise Psychol. 12, 114, 1990.

14. Gottlieb N. H. and Green L. W. Ethnicity and lifestyle health risk: Some possible mechanisms. Am. J. Hith Promot. 8, 37, 1987.

15. Jöreskog K. G. and Sörbom D. Lisrel 7: A Guide to the Program and Applications. SPSS, Chicago, 1988.

16. Pearlin L. I., Meneghan E., Lieberman M. and Mullan J. The stress process. J. Hith soc. Behav. 22, 337, 1981

17. Murrell S. A., Norris F. H. and Grote C. Life events in older adults. In Life Events and Psychological Functioning: Theoretical and Methodological Issues (Edited by Cohen L. H.), p. 96. Sage, Beverly Hills, CA, 1988.

18. Doi T. The Anatomy of Dependence. Kodansha International, Tokyo, 1973.

19. Rook K. S. The negative side of social interaction J. Person. soc. Psychol. 46, 1097, 1984.

20. Krause M. Stress and isolation from close ties in later life. J. Geront. soc. Sci. 46, S183, 1991.

21. Krause N. and Jay G. Stress, social support, and negative interaction in later life. Res. Aging 13, 333, 1991.

22. Lock M. Licorice in Leviathan: The medicalization of care for the Japanese elderly. Culture Med. Psychiatr. 8, 121,1984

23. Plath D. W. Japan: The after years. In Aging and Modernization (Edited by Cowgill D. O. and Holmes L. D.), p. 133. Appelton, Century Crofts, NY, 1972.

24. Free A. O. How Japanese families cope with fragile elderly. J. Geront. soc. Work 15, 39, 1990.

25. Sallis J. F., Patterson T. L., Buono M. J., Atkins C. J. and Nader P. R. Aggregation of physical activity habits in Mexican-American and Anglo families. J. behav. Med. 11, 31, 1988.

26. Kaplan G. A., Lazarus N. B., Cohen R. D. and Leu D. J. Psychosocial factors in the natural history of physical activity. Am. J. prevent. Med. 7, 12, 1991.

27. Cohen S. Psychosocial models of the role of social support in the etiology of physical disease. Hlth Psychol. 7. 269, 1988.

28. Rook K. S., Thuras, P. D. and Lewis M. A. Social control, health risk taking, and psychological distress among the elderly. Psychol. Aging 5, 327, 1990.
29. Hughes M. and Gove W. R. Living alone, social integration, and mental health. Am. J. of Sociol. 87, 48, 1981

30. Umberson D. Family status and health behaviors: Social control as a dimension of social integration. J. Hlth soc. Behav. 28, 306, 1987.

31. Nakane C. Criteria of group formation. In Japanese Culture and Behavior (Edited by Lebra T. S. and Lebra W. P.), p. 171. University of Hawaii Press, Honolulu, 1986.

32. Rodin J., Timko C. and Harris S. The construct of control: Biological and psychosocial correlates. In Annual Review of Gerontology and Geriatrics, Vol. 5, p. 3. Springer, New York, 1985.

33. Krause N., Bennett J. and Tran T. V. Age differences in the acculturation process. Psychol. Aging 4, 321, 1989.

34. Krause N., Neighbors H. and Jackson J. S. Financial strain, system blame, and self-esteem among older blacks. Unpublished manuscript, University of Michigan, School of Public Health.

35. Lurie E. E. The interrelationship of physical and menta illness in the elderly. In Serving the Mentally IIl Elderly Problems and Perspectives (Edited by Lurie E. E. and Swan J. H.), p. 39. Lexington Books, Lexington, MA, 1987.

36. Bollen K. A. Structural Equations with Latent Variables Wiley, New York, 1989.

37. Jay G. M., Liang J., Liu X. and Sugisawa $H$. Patterns of nonresponse in a national survey of the Japanese elderly. J. Geront. soc. Sci. In press.

38. Liang $J$. The structure of self-rated health among the aged. J. Geront. 41, 248, 1986.

39. Stoller E. P. Self-assessments of health by the elderly The impact of informal assistance. J. Hlth soc. Behav. 25, 260, 1984.

40. Abbey A., Abramis D. J. and Caplan R. D. Effects of different sources of social support and social conflict on emotional well-being. Basic appl. Psychol. 6, 111, 1985

41. Wortman C. B. and Dunkel-Schetter C. Conceptual and methodological issues in the study of social support. In Handbook of Psychology and Health, Vol. 5: Stress, p. 63. Lawrence Erlbaum, Hillsdale, NJ, 1987.

42. Barnlund D. C. Communication Styles of Japanese and Americans. Wadsworth, Belmont, CA, 1989.

43. Liang J., Tran T. V., Krause N. and Markides K Differences in the structure of the CES-D Scale in three generations of Mexican Americans. J. Geront. soc. Sci. 44, S110, 1989.

44. Radloff L. The CES-D Scale: A self-report depression scale for rescarch in the general population. Appl. Psychol. Measurement 1, 385, 1977.

45. Huba G. J. and Harlow L. Robust estimation for causal models: A comparison of methods in some developmental datasets. In Life-Span Development and Behavior (Edited by Lerner B. and Featherman D.), p. 348 Academic Press, New York, 1985.

46. Bentler P. and Bonett D. Significance test and goodness of fit in the analysis of covariance structures. Psychol Bull. 88, 588, 1980. 